\title{
Comparativo econômico entre propriedades leiteiras em sistema intensivo de produção: um estudo multicasos
}

\author{
An economic comparison between dairy farms in an intensive production system: a \\ multicases study
}

LOPES, Marcos Aurélio $^{1 *}$; SANTOS, Glauber dos ${ }^{2}$

\author{
${ }^{1}$ Universidade Federal de Lavras, Departamento de Veterinária, Lavras, Minas Gerais, Brasil. \\ ${ }^{2}$ Universidade Federal de Lavras, Programa de Pós-Graduando em Ciências Veterinárias, Lavras, Minas \\ Gerais, Brasil. \\ *Endereço para correspondência: malopes@dmv.ufla.br
}

RESUMO

Objetivou-se, nesta pesquisa, comparar alguns indicadores econômicos de fazendas leiteiras com alto volume de produção diária, em regime de semiconfinamento e confinamento total, localizadas no estado de Minas Gerais, através da metodologia de centro de custos. Foram utilizados os dados coletados entre os meses de março de 2008 a fevereiro de 2009, em seis sistemas de produção de leite, dos quais: três em semiconfinamento e três em confinamento total. Considerou-se centro de custo "produção de leite", isto é, todas as despesas referentes às matrizes em lactação, bem como com vacas secas. Utilizou-se a metodologia do custo total e custo operacional na análise de rentabilidade. Os sistemas de produção em semiconfinamento tiveram viabilidade econômica e condições de produzir no curto, médio e longo prazo, com consequente capitalização dos pecuaristas; enquanto os sistemas de produção em confinamento total apresentaram margem bruta e líquida positivas e o resultado negativo, o que demonstra que têm condições de sobreviver no médio prazo, e, a longo, os pecuaristas podem se descapitalizar. Os itens que exerceram maior "impacto" no custo operacional efetivo foram, em ordem decrescente: a alimentação, mão de obra, despesas diversas, sanidade, energia, ordenha, reprodução, aluguel de máquinas, BST e impostos.

Palavras-chave: análise de rentabilidade, bovinocultura leiteira, centro de custos, custo de produção.

\section{SUMMARY}

The objective of this research was to compare some economic indicators of dairy farms with high daily production volume, in semiconfinement and total confinement regimes, located in the state of Minas Gerais, through the cost center methodology. The data used was collected between the months of March, 2008 and February, 2009, in six milk production systems, three being in semi-confinement and three in total confinement. All of the expenses regarding the lactating matrices, as well as expenses with dry cows were considered as the milk production cost center. The total and operational cost methodology was used for the production cost in the profitability analysis. The semi-confinement production systems had economical viability and producion conditions over the short, medium and long term, with consequent capitalization of the dairy farmers; while the total confinement production systems presented positive gross and liquid margin and negative result, demonstrating to have survival conditions over the medium term, and over the long, the farmers are being decapitalized. The items that exercised higher "impact" on the effective operational cost were, in decreasing order, feeding, labor, miscellaneous expenses, sanitation, energy, milking, reproduction, equipment rental, BST and taxes.

Keywords: cost center, dairy cattle, production costs, profitability analysis. 


\section{INTRODUÇÃOO}

A produção de leite do Brasil "caminha" de sistemas menos produtivos para sistemas com animais de maior produtividade e, obviamente, que envolvem processos tecnológicos mais sofisticados (STOCK et al., 2008).

Independente do sistema de produção explorado, faz-se necessário conhecer os custos de produção de cada produto, seja do litro de leite, de uma novilha ao parto, seja ainda, do quilo de forragem produzido, na intenção de localizar os pontos de estrangulamento e tomar as devidas decisões para maximizar os lucros. Para Oaigen et al. (2008), a metodologia dos centros de custos se baseia no mapeamento dos centros produtivos, o que permite ao empresário rural mensurar o custo de produção por meio desses centros e verificar o impacto que determinados processos e/ou tecnologias causam ao sistema, especificamente no custo final do produto.

Dados de custo de produção têm sido utilizados também para quantificar ineficiências econômicas (TUPY \& YAMAGUCHI, 2002), avaliar o efeito da escala de produção (LOPES et al., 2006), do tipo de sistema de criação (LOPES et al., 2007), e ainda do nível tecnológico (LOPES et al., 2009), bem como comparar propriedades leiteiras (CARVALHO et al., 2009). Porém, nenhum desses estudos apurou os custos de produção através da metodologia de centro de custos, em propriedades com alto volume de produção diária. Em tais pesquisas, adotaram a apuração de custo da atividade leiteira como um todo, talvez pela menor complexidade nas coletas de dados.

Assim, objetivou-se, nesta pesquisa, comparar alguns indicadores econômicos de fazendas leiteiras, em sistema intensivo de produção, em regime de semiconfinamento e confinamento total, localizadas no estado de Minas Gerais, através da metodologia de centro de custos, no intuito de elucidar o comportamento do custo de produção de cada um dos produtos da atividade leiteira, separadamente. Pretendeu-se, ainda, identificar os componentes que exerceram a maior influência sobre $\mathrm{o}$ custo operacional efetivo.

\section{MATERIAL E MÉTODOS}

Foram utilizados os dados de seis sistemas de produção de leite, localizados na região central mineira e sul/sudoeste de Minas, coletados entre os meses de março de 2008 a fevereiro de 2009. Segundo o IBGE (2010), a produtividade média é maior que 2.500 e de 500 a $1.000 \mathrm{~kg}$ de leite/vaca/ano, nas regiões central mineira e sul/sudoeste de Minas, respectivamente. Os sistemas de produção foram divididos em dois grupos: semiconfinamento e confinamento total, e cada grupo constituído por três sistemas de produção, o que correspondeu à produção média diária de 19.867,04 e 17.982,30 kg, respectivamente, em cada grupo. Considerou-se como centro de custo "produção de leite", isto é, todos os custos atribuídos às matrizes em lactação, bem como com vacas secas.

Para melhor controle das despesas, em todos os sistemas de produção havia um almoxarifado para estocar os itens de consumo e um funcionário com dedicação exclusiva. Para dar saída em algum desses bens, era necessária uma requisição, com a indicação para qual centro de custo tal produto se destinaria. Dentro do centro de custo existia um plano de contas, dividido em receitas e despesas. Como receitas, as opções, a 
saber, eram classificadas em: venda de leite, de animais ou subprodutos. As despesas foram divididas em: concentrado proteico, concentrado energético, minerais/aditivos, forragem, salários, encargos sociais, EPI/uniforme, diarista, assistência técnica, mão de obra de terceiros, sanidade, insumos de reprodução, hormônios, BST, higiene de ordenha, manutenção periódica, impostos e taxas, energia elétrica, combustível e lubrificante, aluguel de máquinas, despesas administrativas, material para manejo de animais, manutenção de benfeitorias, frete, telefone e outros.

Os sistemas de produção em semiconfinamento foram caracterizados por apresentarem, na sua quase totalidade, matrizes mestiças Holandês-Gir, cujo grupos genéticos variaram entre $1 / 2$, $3 / 4,7 / 8$ ou 15/16. A estimativa de produção de leite variou de 4.759,60 a $6.336,40 \mathrm{~kg} / \mathrm{vaca} / \mathrm{ano}$, o que corresponde à vacas em lactação com média de 13,04 a $17,36 \mathrm{~kg}$ de leite/dia, respectivamente. Todas as matrizes em lactação eram ordenhadas duas vezes ao dia. Já os sistemas de produção em confinamento total, apresentavam vacas especializadas para produção de leite, cuja maioria dos animais eram puros de origem (PO), pertencentes à raça Holandesa, e apresentavam média de produção acima de $8.000 \mathrm{~kg} / \mathrm{vaca} / \mathrm{ano}$. Durante todo o ano, os animais receberam, no cocho, dieta completa e eram ordenhados três vezes ao dia.

Considerou a depreciação das matrizes da seguinte maneira: como valor final, adotou-se o valor da venda de uma vaca gorda (550kg de peso vivo), vendida a preço de arroba $(\mathrm{R} \$ 65,00)$; o valor inicial foi o custo total de uma novilha, ao primeiro parto, e a vida útil foi estimada em função da taxa de descarte involuntário de cada sistema de produção.
A análise de rentabilidade contemplou a metodologia do custo operacional, proposta por Matsunaga et al. (1976) e do custo total, de acordo com Lopes et al. (2007). Considerou-se como indicadores de rentabilidade: a margem bruta (receita menos custo operacional efetivo), margem líquida (receita menos custo operacional total) e resultado (receita menos custo total). Além desses, estimouse ainda lucratividade 1 , que foi calculada ao se obter o resultado e dividi-lo pela receita total (Lucratividade $1(\%)=$ Resultado/Receita total); e a rentabilidade 1, obtida pela divisão do resultado pelo total imobilizado mais o custo operacional efetivo (Rentabilidade $1(\%)$ $=$ Resultado/(Total imobilizado + Custo operacional efetivo)) - (SEBRAE, 1998). Como lucratividade 2, considerou-se a divisão da margem líquida pela receita total (Lucratividade $2(\%)=$ Margem líquida /Receita total); e como rentabilidade 2, considerou-se a divisão da margem líquida pelo total imobilizado mais o custo operacional efetivo (Rentabilidade $2(\%)=$ Margem líquida/(Total imobilizado + Custo operacional efetivo)). Esses dois últimos indicadores foram estimados segundo Lopes et al. (2011). A variação do inventário em rebanho foi calculada como se a diferença fosse, em reais ( $\mathrm{R} \$)$, do inventário em animais do final e do início do período de estudo.

Esta pesquisa foi desenvolvida com base no conceito de estudo de caso, descrito por Yin (1984). Os dados foram sumarizados por meio de estatísticas descritivas simples e agrupados em tabelas, para uma melhor apresentação, comparação e discussão dos resultados (LOPES et al., 2004).

A amostragem não probabilística por julgamento foi realizada ao se considerar a disponibilidade e qualidade dos dados por parte dos produtores. Todavia, a eles não foram aplicados testes estatísticos, 
pois o objetivo foi avaliar a rentabilidade, bem como identificar os componentes que exerceram influência sobre o custo operacional efetivo.

\section{RESULTADOS E DISCUSSÃO}

O valor do "patrimônio investido sem considerar a terra", é muito diferente no item benfeitorias, devido às instalações destinadas aos animais em confinamento, ou seja, nos sistemas em semiconfinamento ocorreu um maior investimento em animais, enquanto nos sistemas de confinamento total os maiores investimentos foram em benfeitorias. Ao analisar o total imobilizado por matriz em lactação, observou-se que a média nos sistemas em confinamento total foi $\mathrm{R} \$ 6.541,25$, valor maior do que nos sistemas em semiconfinamento ( $\$$ \$18.516,08 $\mathrm{R} \$ 11.974,84)$. Entretanto, quando se compara o total imobilizado por $\mathrm{kg}$ de produzido por dia, a diferença entre os sistemas foi baixa $(\mathrm{R} \$ 64,47=\mathrm{R} \$ 825,90$ - R\$761,43) - (Tabela 1), devido à maior produtividade das matrizes nos sistemas em confinamento total.

Com relação ao capital imobilizado por matriz em lactação, observa-se, na Tabela 1 , que os sistemas em semiconfinamento foram menores, possivelmente por apresentarem uma quantidade bem mais elevada de matrizes em lactação $(465,67)$ e menor preço médio de uma matriz ( $\mathrm{R} \$ 3.833,33)$. Em contrapartida, os sistemas em confinamento total possuíam, em média, 277,33 matrizes em lactação e cada uma avaliada em $\mathrm{R} \$ 4.266,67$, o que explica parte do maior capital imobilizado por matriz em lactação.

$\mathrm{O}$ valor investido em matrizes (vacas em lactação + vacas secas) foi $o$ item com maior representatividade do "patrimônio investido sem considerar a terra", em média, $80,00 \%$ e $48,05 \%$ nos sistemas em semiconfinamento e confinamento total, respectivamente. A alta representação desse item, no total imobilizado, evidencia a importância do cuidado que se deve ter com as mesmas, como, por exemplo, no momento da aquisição, no manejo diário, no ambiente adequado, entre outros, de modo a proporcionar condições para que se possa ter máxima produtividade $\mathrm{e}$, consequentemente, maior retorno do capital. Os valores investidos em matrizes são considerados custos fixos; portanto, devem-se atingir altas produções por animal para que eles possam ser "diluídos", o que acarreta baixos percentuais do custo total.

Na composição da receita total, a venda de leite, de animais e de subprodutos representou $85,34 \%, \quad 14,46 \%$ e $0,20 \%$ no semiconfinamento e $97,76 \%$, $2,19 \%$ e $0,00 \%$ no confinamento total, respectivamente. A maior representatividade da comercialização de animais na receita total do semiconfinamento contribuiu para que a rentabilidade média fosse 5,69\%, enquanto, no confinamento total, ela foi negativa $(-1,92 \%)$. Essa maior contribuição deveu-se, principalmente, ao fato de um dos sistemas de produção ter adotado uma comercialização estratégica de animais, de forma a conseguir bons preços nos animais comercializados. Ela pode ocorrer também em sistemas de produção que passam, principalmente, pelas seguintes situações: pequeno produtor, cujos animais não são especializados para a produção de leite, teoricamente seriam animais de dupla aptidão; produtores que passam por uma crise financeira, vendem animais, e produtores que têm boa genética e comercializam melhor os animais, que foi o caso dos sistemas de produção em semiconfinamento. 
Tabela 1. Comparativo dos recursos disponíveis nos centros de custo produção de leite em sistemas de produção em semiconfinamento (SeConf) e confinamento total (ConfTo), durante o período de março de 2008 a fevereiro de 2009

\begin{tabular}{|c|c|c|c|c|c|c|}
\hline \multirow{2}{*}{ Especificação } & \multicolumn{3}{|c|}{ SeConf } & \multicolumn{3}{|c|}{ ConfTo } \\
\hline & Média & DP & $\%$ & Média & DP & $\%$ \\
\hline Valor do patrimônio em terra $(\mathrm{R} \$)$ & $2.096 .466,67$ & $1.494 .862,49$ & 46,59 & $2.237 .966,67$ & $1.169 .411,99$ & 42,32 \\
\hline Valor do patrimônio sem terra $(\mathrm{R} \$)$ & $2.403 .481,07$ & $1.712 .831,66$ & 53,41 & $3.049 .746,78$ & $1.677 .709,79$ & 57,68 \\
\hline Valor em benfeitorias ( $\mathrm{R} \$$ ) & $261.766,67$ & $164.019,03$ & 10,89 & $1.189 .781,08$ & $703.029,19$ & 39,01 \\
\hline Valor em máquinas ( $\mathrm{R} \$$ ) & $161.115,87$ & $114.640,33$ & 6,70 & $310.561,00$ & $215.913,24$ & 10,18 \\
\hline Valor em equipamentos e implementos $(\mathrm{R} \$)$ & $57.765,20$ & $37.952,34$ & 2,40 & $84.071,37$ & $3.398,80$ & 2,76 \\
\hline Valor em animais $(\mathrm{R} \$)$ & $1.922 .833,33$ & $1.430 .466,39$ & 80,00 & $1.465 .333,33$ & $795.027,88$ & 48,05 \\
\hline Área $(\mathrm{ha})^{*}$ & 203,18 & 149,35 & - & 214,18 & 87,95 & - \\
\hline Quantidade média de matrizes (lactação + seca) & 571,00 & 537,01 & - & 339,33 & 179,02 & - \\
\hline Quantidade média de matrizes em lactação & 465,67 & 447,95 & - & 277,33 & 130,48 & - \\
\hline Quantidade de mão de obra (homem/dia) & 8,67 & 5,51 & - & 10,67 & 4,62 & - \\
\hline Média diária de leite produzido (kg) & $6.622,35$ & $5.402,84$ & - & $6.227,15$ & $2.863,10$ & - \\
\hline Total imobilizado $(\mathrm{R} \$)$ & $4.499 .947,73$ & $3.138 .982,51$ & - & $5.287 .713,45$ & $2.753 .945,18$ & - \\
\hline Total imobilizado por ha $(\mathrm{R} \$)$ & $22.609,80$ & $2.677,40$ & - & $23.581,09$ & $4.072,69$ & - \\
\hline Total imobilizado por matriz em lactação (R\$) & $11.974,84$ & $5.133,76$ & - & $18.516,08$ & $2.907,76$ & - \\
\hline Total imobilizado por $\mathrm{kg}$ de leite produzido por dia $(\mathrm{R} \$)$ & 761,43 & 281,54 & - & 825,90 & 110,17 & - \\
\hline
\end{tabular}


Lopes et al. (2007) relataram que $11,66 \%$ da receita total foi com a venda de animais; essa porcentagem foi superior à encontrada pelos sistemas em confinamento total, possivelmente pelas diferentes produções $288,86 \mathrm{~kg}$ de leite/dia (LOPES et al., 2007) versus $6.227,15 \mathrm{~kg}$ de leite/dia (presente estudo). Tal fato mostra que a venda de animais tende a ser mais representativa em sistema com menor comercialização diária de leite, exceto para sistemas de produção que adotam a venda estratégica de animais. Segundo outros pesquisadores (MARQUES et al., 2002; LOPES et al., 2005; 2007), a receita com a venda de animais variou de $28,08 \%$ a $4,16 \%$. Tais valores evidenciam que ocorre grande variação no percentual da composição da receita. O que vai definir a maior ou menor venda de animais são as metas do sistema de produção, a necessidade de levantar receitas (LOPES et al., 2009), os aspectos referentes à saúde do rebanho (DEMEU et al, 2011), bem como a qualidade genética das matrizes.

Quando se trata de apuração de custo por centro produtivo, a comercialização de matrizes aumenta as receitas e, em consequência dessas vendas, o item depreciação também aumenta, uma vez que reduz a vida útil das matrizes e eleva a depreciação das mesmas, o que torna o custo de produção um pouco mais elevado. No entanto, não foi isso que aconteceu entre os sistemas aqui comparados, pois, no confinamento total, a venda de animais foi menor e a depreciação de matrizes maior (Tabela 2). Fato explicado pela maior taxa de descarte involuntário $(22,84$ versus $17,49 \%$ ) e, ainda, pelo maior custo total médio das novilhas de reposição ( $\mathrm{R} \$ 3.240,28$ versus $\mathrm{R} \$ 2.857,15)$ nos sistemas de produção em confinamento total e semiconfinamento, respectivamente. Dessa forma, o maior custo, com a depreciação das matrizes, contribuiu para que os sistemas em confinamento total apresentassem uma rentabilidade negativa. Isso evidencia que esforços gerenciais se fazem necessários na intenção de reduzir a taxa de descarte involuntário, bem como no custo das novilhas ao primeiro parto.

Apenas nos sistemas em semiconfinamento ocorreu apuração de receita com a venda de subprodutos (esterco), o que representou $0,20 \%$ da receita total; já no confinamento total, esse foi utilizado na irrigação do tifton e ainda aplicado em áreas de agricultura destinadas às matrizes. Segundo Lopes et al. (2005), essa pode ser uma alternativa de renda e representar até $1,51 \%$ da receita total ou reduzir o uso de fertilizantes químicos, quando aplicados em áreas de agricultura.

A variação do rebanho foi positiva e bem maior no confinamento total (Tabela 2). Tal fato pode ser um indício de que os rebanhos estejam em crescimento, ou seja, os produtores têm expandido a atividade em maior grau do que os produtores do semiconfinamento. Configura-se como um indicador da variação patrimonial em matrizes e é útil na tomada de decisão, pois podem existir sistemas de produção que obtenham resultado positivo na atividade, quando, no entanto, ocorre redução patrimonial em matrizes para apurar receitas e viceversa. Portanto, alguns cuidados merecem atenção no que se refere a esse indicador e, sobretudo, pelo fato de não se tratar de dinheiro em espécie (moeda), palpável.

No sistema de produção confinamento total, por exemplo, ocorreu valorização média do rebanho de $\mathrm{R} \$ 97.433,33$, durante o período estudado. No entanto, se o produtor quiser destinar esse valor para pagar algum compromisso, terá que vender animais. A venda, em determinadas ocasiões, pode não ser tão fácil, devido ao fato de a liquidez dos 
Rev. Bras. Saúde Prod. Anim., Salvador, v.13, n.3, p.591-603 jul./set., 2012 http://www.rbspa.ufba.br ISSN 15199940

animais, em alguns momentos, não ser tão alta. Outro ponto que deve ser considerado é que a morte de animais pode ocorrer, o que reduzirá a receita futura da atividade, o que interfere na lucratividade e na rentabilidade. Os sistemas em confinamento apresentaram resultados negativos, de modo que não foi possível remunerar a terra e o capital investido; diferentemente dos sistemas em semiconfinamento.

Tabela 2. Resumo das análises de rentabilidades dos centros de custos produção de leite dos sistemas de produção semiconfinamento (SeConf) e confinamento total (ConfTo), durante o período de março de 2008 a fevereiro de 2009, em R\$

\begin{tabular}{|c|c|c|c|c|}
\hline \multirow{2}{*}{$\begin{array}{l}\text { Sistema de produção } \\
\text { Especificação }\end{array}$} & \multicolumn{2}{|c|}{ SeConf } & \multicolumn{2}{|c|}{ ConfTo } \\
\hline & Média & DP & Média & DP \\
\hline Receita & $2.192 .794,05$ & $2.154 .893,99$ & $1.914 .745,20$ & $926.602,35$ \\
\hline Leite & $1.875 .097,03$ & $1.642 .896,22$ & $1.872 .744,27$ & $895.537,49$ \\
\hline Animais & $317.048,34$ & $517.025,32$ & $42.000,93$ & $36.483,37$ \\
\hline Subprodutos & 648,68 & $1.123,55$ & 0,00 & 0,00 \\
\hline Custo operacional total (COT) & $1.584 .962,04$ & $1.386 .710,94$ & $1.870 .555,18$ & $846.491,46$ \\
\hline Custo operacional efetivo (COE) & $1.549 .399,83$ & $1.365 .183,98$ & $1.788 .143,72$ & $834.424,95$ \\
\hline Depreciação & $35.562,21$ & $21.581,23$ & $82.411,46$ & $17.172,84$ \\
\hline Depreciação da infraestrutura & $20.264,69$ & $14.643,67$ & $55.073,83$ & $14.649,56$ \\
\hline Depreciação de matrizes & $15.297,51$ & $9.092,63$ & $27.337,64$ & $13.190,41$ \\
\hline Custo total (CT) & $1.700 .328,12$ & $1.470 .624,88$ & $1.995 .276,41$ & $899.743,78$ \\
\hline Custo fixo (CF) & $149.890,17$ & $106.027,16$ & $204.454,09$ & $67.977,42$ \\
\hline Remuneração da terra & $88.992,84$ & $65.416,11$ & $93.812,30$ & $38.523,91$ \\
\hline Remuneração do capital investido & $22.499,74$ & $15.694,91$ & $26.438,57$ & $13.769,73$ \\
\hline Remuneração do empresário & 0,00 & 0,00 & 0,00 & 0,00 \\
\hline Impostos fixos (IPVA + ITR) & $2.835,39$ & $3.738,44$ & $1.791,76$ & 880,99 \\
\hline Depreciação & $35.562,21$ & $21.581,23$ & $82.411,46$ & $17.172,84$ \\
\hline Depreciação da infraestrutura & $20.264,69$ & $14.643,67$ & $55.073,83$ & $14.649,56$ \\
\hline Depreciação de matrizes & $15.297,51$ & $9.092,63$ & $27.337,64$ & $13.190,41$ \\
\hline Custo variável (CV) & $1.550 .437,95$ & $1.364 .956,31$ & $1.790 .822,32$ & $836.153,71$ \\
\hline Custo operac. efetivo (s/impostos) & $1.546 .564,45$ & $1.361 .543,35$ & $1.786 .351,96$ & $834.067,65$ \\
\hline Remuneração do capital de giro & $3.873,50$ & $3.412,96$ & $4.470,36$ & $2.086,06$ \\
\hline Margem bruta & $643.394,22$ & $791.095,52$ & $126.601,48$ & $217.679,23$ \\
\hline Margem líquida & $607.832,01$ & $769.749,90$ & $44.190,01$ & $202.352,94$ \\
\hline Resultado (lucro ou prejuízo) & $492.465,93$ & $685.364,50$ & $-80.531,21$ & $182.482,68$ \\
\hline Variação do rebanho (Vr) & $47.166,67$ & $10.128,34$ & $97.433,33$ & $102.786,01$ \\
\hline Margem bruta $+\mathrm{Vr}$ & $690.560,89$ & $783.623,35$ & $224.034,81$ & $319.667,54$ \\
\hline Margem líquida $+\mathrm{Vr}$ & $654.998,68$ & $762.306,62$ & $141.623,35$ & $303.933,93$ \\
\hline Resultado (lucro ou prejuízo) $+\mathrm{Vr}$ & $539.632,60$ & $677.894,20$ & $16.902,12$ & $278.590,38$ \\
\hline Lucratividade $1(\%)$ & 15,63 & 10,46 & $-7,02$ & 11,77 \\
\hline Rentabilidade $1(\%)$ & 5,69 & 5,11 & $-1,92$ & 3,30 \\
\hline Lucratividade $2(\%)$ & 22,06 & 8,66 & $-0,33$ & 11,33 \\
\hline Rentabilidade $2(\%)$ & 7,60 & 5,11 & $-0,09$ & 3,17 \\
\hline Quantidade de leite (kg/ano) & $2.417 .156,53$ & $1.972 .037,74$ & $2.294 .544,92$ & $1.068 .987,84$ \\
\hline Quantidade equivalente leite (kg/ano) & $2.812 .831,73$ & $2.605 .827,24$ & $2.345 .839,61$ & $1.106 .940,02$ \\
\hline
\end{tabular}

1 - Fórmula considerando o resultado da atividade; 2 - Fórmula considerando a margem líquida da atividade. DP = Desvio padrão 
Rev. Bras. Saúde Prod. Anim., Salvador, v.13, n.3, p.591-603 jul./set., 2012 http://www.rbspa.ufba.br ISSN 15199940

$\mathrm{Na}$ Tabela 3, pode-se visualizar a contribuição de cada item componente do custo operacional efetivo nos sistemas de produção em semiconfinamento e em confinamento total, em porcentagem. A alimentação representou 60,95 e $53,19 \%$ do custo operacional efetivo, no semiconfinamento e no confinamento total, respectivamente. Observa-se que a alimentação, percentualmente, foi maior no semiconfinamento, devido ao menor custo operacional efetivo, e os demais componentes do custo tiveram menor representação, quando comparados aos sistemas de confinamento total.

Tabela 3. Contribuição de cada item no custo operacional efetivo nos centros de custo de produção de leite em semiconfinamento (SeConf) e confinamento total (ConfTo), durante o período de março de 2008 a fevereiro de 2009, em \% do custo operacional efetivo COE e \% da receita do leite (RL)

\begin{tabular}{lrrrr}
\hline \multirow{2}{*}{ Especificação } & \multicolumn{2}{c}{$\%$ do COE } & \multicolumn{2}{c}{$\%$ da } \\
\cline { 2 - 5 } & SeConf & ConfTo & SeConf & ConfTo \\
\hline Alimentação & 60,95 & 53,19 & 50,26 & 58,78 \\
Concentrado proteico & 15,68 & 19,80 & 12,95 & 21,50 \\
Concentrado energético & 22,89 & 16,29 & 18,85 & 18,21 \\
Minerais/aditivos & 2,94 & 6,69 & 2,43 & 7,58 \\
Forragem & 19,44 & 10,41 & 16,03 & 11,49 \\
Mão de obra & 11,76 & 15,81 & 9,71 & 16,83 \\
Salário & 7,54 & 7,43 & 6,22 & 8,07 \\
Encargos & 0,47 & 1,27 & 0,39 & 1,35 \\
EPI/Uniforme & 0,14 & 0,16 & 0,12 & 0,17 \\
Diarista & 0,15 & 0,28 & 0,13 & 0,29 \\
Assistência técnica & 2,65 & 5,80 & 2,19 & 6,05 \\
Mão de obra de terceiros & 0,82 & 0,86 & 0,67 & 0,90 \\
Sanidade & 5,22 & 5,11 & 4,30 & 5,65 \\
Reprodução & 2,74 & 4,28 & 2,27 & 4,52 \\
Insumos reprodução & 1,90 & 3,42 & 1,57 & 3,59 \\
Hormônios & 0,84 & 0,86 & 0,69 & 0,93 \\
BST & 1,20 & 4,88 & 1,00 & 5,24 \\
Ordenha & 2,58 & 2,15 & 2,14 & 2,40 \\
Higiene de ordenha & 1,61 & 1,10 & 1,34 & 1,24 \\
Manutenção periódica & 0,97 & 1,04 & 0,80 & 1,16 \\
Impostos e taxas & 1,06 & 0,63 & 0,88 & 0,61 \\
Energia & 2,21 & 4,72 & 1,81 & 5,06 \\
Energia elétrica & 1,67 & 3,18 & 1,38 & 3,46 \\
Combustível e lubrificante & 0,53 & 1,54 & 0,44 & 1,60 \\
Aluguel de máquinas & 1,84 & 1,89 & 1,53 & 2,09 \\
Despesas diversas & 10,42 & 7,33 & 8,16 & 8,42 \\
Despesas administrativas & 4,90 & 4,38 & 4,05 & 5,23 \\
Manejo de animais & 0,23 & 0,56 & 0,19 & 0,61 \\
Manutenção de benfeitorias & 0,81 & 0,97 & 0,67 & 1,05 \\
Frete & 1,32 & 0,04 & 1,10 & 0,04 \\
Telefone & 0,33 & 0,23 & 0,27 & 0,24 \\
Outros & 2,83 & 1,15 & 2,35 & 1,25 \\
\hline Total do COE & 100,00 & 100,00 & 82,05 & 97,82 \\
\hline & & & & \\
& & & & \\
& & & &
\end{tabular}


Ressalta-se a importância no cuidado de se comparar percentuais de custo entre diferentes sistemas de produção, uma vez que os mesmos apresentam custos diferentes. Possivelmente, esse maior dispêndio com as despesas alimentares está relacionado à maior produtividade por matriz em lactação, o que leva a oferecer uma dieta mais rica nutricionalmente, a fim de atender à exigência do animal. No entanto, essas dietas diferentes podem ter contribuído para um leite com maior teor de sólidos totais no confinamento total, se comparado ao semiconfinamento, uma vez que os volumes médios diários de leite comercializado entre os sistemas foram semelhantes e ocorreu valorização de $4,96 \%$ a mais pelo leite do confinamento total. Outros fatores podem estar relacionados com essa valorização ou penalização, tais como: qualidade e estacionalidade da produção. Porém, nesta pesquisa, dados da qualidade do leite não foram levantados, o que impossibilita fazer uma análise financeira. Tozer et al. (2003), ao avaliarem a análise econômica de estratégias alimentar, concluíram que o custo diário de animais alimentados com dieta completa foi maior (U\$4,16) do que na pastagem (U\$2,38). Entretanto, a receita com a venda de leite, gordura e proteína proporcionou uma maior margem bruta que foi de U\$\$5,61 com a dieta completa e U\$\$5,31 para o sistema alimentar baseado em pastagem. No entanto, Silva et al. (2008), ao estudarem também a viabilidade de diferentes sistemas de alimentação, concluíram que o tratamento com $20 \%$ de suplementação apresentou o melhor resultado econômico, com a maior margem bruta de $\mathrm{R} \$ 0,2198 / \mathrm{kg}$ de leite, enquanto, no sistema com $100 \%$ de suplementação, a margem bruta foi de $\mathrm{R} \$ 0,1368 / \mathrm{kg}$ de leite.
No item forragem, consideraram-se todas as despesas de adubação das pastagens e despesas com a forrageira utilizada na suplementação durante o inverno (canade-açúcar e silagem de milho), nos sistemas em semiconfinamento, e silagem de milho e tifton fresco picado no cocho, nos sistemas de confinamento total. As despesas com forragem representaram $19,44 \%$ do custo operacional efetivo nos sistemas em semiconfinamento e $10,41 \%$ nos confinamento total, respectivamente (Tabela 3). Esse maior custo, principalmente da pastagem, comparado ao da silagem de milho, foi devido, talvez, à adubação programada para produções maiores de matéria seca do que a alcançada; à elevação no preço de adubos e/ou à eficiência na produção da silagem de milho, de modo a proporcionar altas produtividades. Parte da menor média de produção por matriz em lactação apresentada pelos sistemas em semiconfinamento pode estar relacionada à forrageira utilizada para suplementação (cana-de-açúcar), pois segundo Corrêa et al. (2003), ocorre maior produções de leite em dietas à base de silagem de milho, quando comparadas com cana-de-açúcar e ureia. As despesas com sanidade foram maiores no confinamento total do que no semiconfinamento (Tabela 3), principalmente, devido ao fato de esse sistema possuir animais mais propensos às principais doenças que acometem $o$ rebanho bovino, ao maior desafio aos animais, às dietas com baixo teor de fibra e ao piso de concreto. Em um estudo de custos e resultados do tratamento de sequelas de laminite bovina em vacas em lactação no sistema free stall, Ferreira et al. (2004) constataram que elas provocaram um prejuízo de US\$74,60 por animal alojado no rebanho. Esse valor ainda não incluía a perda na produção de leite e prováveis problemas reprodutivos. 
Animais mestiços, menor produção e ambiente mais favorável à manifestação do estro podem ter sido alguns dos fatores que contribuíram para que o sistema semiconfinamento tivesse menor despesa com reprodução (Tabela 3). A utilização de uma maior quantidade de doses de sêmen por concepção e do uso da transferência de embrião em um dos sistemas do confinamento total afetou de maneira a aumentar as despesas com esse item. Em vários estudos, tem sido evidenciado que a eficiência reprodutiva de vacas leiteiras tem declinado com o aumento da produção, possivelmente pelo fato de vacas leiteiras de alta produção terem menores concentrações de progesterona no plasma (VASCONCELOS et. al., 1999), talvez, por causa da maior ingestão de matéria seca que aumenta o fluxo de sangue e altera a concentração de progesterona.

$\mathrm{O}$ uso do BST foi utilizado nos dois sistemas de produção, porémmais acentuado no confinamento total do que no semiconfinamento (Tabela 3). Possivelmente, foi utilizado em uma quantidade maior de animais, com a intenção de aumentar a produção e "diluir" alguns custos, principalmente, os fixos, de modo a otimizar alguns itens do custo variável. Segundo Lucci et al. (1998), os resultados obtidos com a aplicação do BST aumentou o leite em $4,95 \mathrm{~kg} / \mathrm{vaca} / \mathrm{dia}$ e a gordura em $0,20 \mathrm{~kg} / \mathrm{vaca} / \mathrm{dia}$.

Como indicador da eficiência reprodutiva, pode-se observar a porcentagem de vacas em lactação em relação ao total de vacas, que foi, em média, de $80,18 \%$ no semiconfinamento e de $83,27 \%$ no confinamento total. Essa maior porcentagem no confinamento total pode ser atribuída ao maior uso da técnica de transferência de embrião, à maior taxa de descarte e, ainda, devido à maior quantidade de funcionários em um dos sistemas de produção, os quais eram destinados a uma observação de cio mais intensa. Vale salientar que, em ambos os sistemas, essa relação pode ser considerada excelente. A observação mais intensa do cio pode-se ter exercido inflência, pois, segundo Lopez et al. (2004), ocorre redução na duração do estro de vacas de leite com alta produção, o que pode estar associado com a redução do estradiol circulante.

A produtividade média de leite por vaca em lactação foi de $15,62 \mathrm{e}$ $22,58 \mathrm{~kg} / \mathrm{vaca} / \mathrm{dia}$, nos sistemas em semiconfinamento e confinamento total, respectivamente. Parte da diferença pode ser atribuída à fatores genéticos (mestiços Holandês-Zebu versus Holandês puro de origem) e, em parte, devido ao gasto de energia dos animais em pastejo. Segundo Bargo et al. (2002), vacas em lactação, que recebiam dieta completa, produziram $25,19 \%$ (38,1 versus $28,5 \mathrm{~kg} / \mathrm{dia})$ mais leite do que vacas sujeitas ao pastejo e suplementadas com concentrado. Kolver et al. (2000) e White et al. (2002) encontraram aumentos da ordem de $34,07 \%$ e $11 \%$, com dietas completas, na comparação com pastagem mais concentrado. A diferença na produção de leite se dá, principalmente, por não atender aos requerimentos de energia no pastejo, uma vez que a ingestão de matéria seca é menor (BARGO et al., 2002) e os animais gastam mais energia ao se alimentarem (AGNEW et al., 2000). Além disso, deve-se considerar a menor eficiência energética apresentada pelos animais no pastejo, em virtude da maior produção de metano, se comparados aos animais que recebem dieta com alto concentrado (LANA \& RUSSUELL, 2001).

A relação depreciação/custo operacional total fornece uma informação da eficiência de utilização dos recursos disponíveis para a produção de leite, quando se comparam sistemas semelhantes e dá uma idéia da 
Rev. Bras. Saúde Prod. Anim., Salvador, v.13, n.3, p.591-603 jul./set., 2012 http://www.rbspa.ufba.br ISSN 15199940

infraestrutura necessária para a produção de leite, quando se comparam sistemas diferentes. A depreciação representou $2,62 \%$ e $4,97 \%$ do custo operacional total nos sistemas em semiconfinamento e no confinamento total, respectivamente. A diferença pode ser atribuída à maior depreciação de matrizes e ao alto maior valor imobilizado por vaca em lactação nos sistemas em confinamento total. Tal fato exige que esse tipo de sistema seja composto por animais de alta produção, para "diluir" o custo com a depreciação.

$\mathrm{O}$ custo fixo é composto pela depreciação, impostos fixos e custo de oportunidade da terra, do capital investido e do empresário (quando houver). A relação custo fixo e o custo total foi de $9,83 \%$ e $6,02 \%$, no semiconfinamento e no confinamento total, respectivamente. $\mathrm{O}$ custo fixo foi maior no semiconfinamento, devido ao grande impacto da remuneração da terra, ou seja, em sistemas de produção em semiconfinamento nos quais a terra é bem valorizada, o custo fixo pode se apresentar maior do que em sistemas de confinamento.

$\mathrm{Na}$ análise econômica, por apresentarem margem bruta, líquida e resultado positivos, os sistemas de produção em semiconfinamento tiveram viabilidade econômica e condições de produzir no curto, médio e longo prazo, com consequente capitalização dos pecuaristas. Os sistemas de produção em confinamento total apresentaram margem bruta e líquida positivas e o resultado negativo, o que demonstra ter condições de sobreviver no médio prazo, e, a longo, os pecuaristas estão em fase de descapitalização. Os itens que exerceram maior "impacto" no custo operacional efetivo foram, em ordem decrescente, a alimentação, mão de obra, despesas diversas, sanidade, energia, ordenha, reprodução, aluguel de máquinas, BST e impostos.

\section{AGRADECIMENTOS}

Os autores agradecem a FAPEMIG e ao $\mathrm{CNPq}$ pelo apoio financeiro na realização deste trabalho.

\section{REFERÊNCIAS}

AGNEW, R.E.; YAN, T. Impact of recent research on energy feeding systems for dairy cattle. Livestok Production

Science, v.66, n.3, p.197-215, 2000.

BARGO, F.; MULLER, L.D.; DELAHY, J.E.; CASSIDY, T.W. Performance of high producing dairy cows with three different feeding systems combining pasture and total mixed rations. Journal of Dairy Science, v.85, n.11, p.29482963, 2002.

CARVALHO, F.M.; RAMOS, O.E.; LOPES, M.A. Análise comparativa dos custos de produção de duas propriedades leiteiras no município de Unai - MG, no período de 2003 e 2004. Ciência e Agrotecnologia, v.33, p.1705-1711, 2009.

CORRÊA, C.E.S.; PEREIRA, M.N.; OLIVEIRA, S.G.; RAMOS, M.H. Performance of holstein cows fed sugarcane or corn silages of different grain textures. Scientia Agricola, v.60, n.4, p.621-629, 2003.

DEMEU, F.A.; LOPES, M.A.; COSTA, G.M.; ROCHA, C.M.B.M.; SANTOS, G.; FRANCO NETO, A. Influência do descarte involuntário de matrizes no impacto econômico da mastite em rebanhos leiteiros. Ciência e

Agrotecnologia, v.35, n.1, p.195-202, 2011. 
Rev. Bras. Saúde Prod. Anim., Salvador, v.13, n.3, p.591-603 jul./set., 2012 http://www.rbspa.ufba.br ISSN 15199940

FERREIRA, P.M.; LEITE, R.C.; CARVALHO, A.U.; FACURY FILHO, E.J.; SOUZA, R.C.; FERREIRA, M.G. Custo e resultados do tratamento de sequielas de laminite bovina: relato de 112 casos em vacas em lactação no sistema free-stall. Arquivo Brasileiro de Medicina Veterinária e Zootecnia, v.56, n.5, p.589-594, 2004.

\section{INSTITUTO BRASILEIRO DE GEOGRAFIA E ESTATÍSTICA - IBGE. Pesquisa pecuária municipal. \\ Disponível em: \\ $<$ http://www.sidra.ibge.gov.br>. Acesso em: 20 jul. 2010.}

KOLVER, E.S.; NAPPER, A.R.; COPEMAN, P.J.A.; MULLER, L.D. Synchronization of ruminal degradation of supplemental carbohydrate with pasture nitrogen in lactating dairy cows. Journal of Dairy Science, v.81, n.7, p.2017-2028, 2000.

LANA, R.P.; RUSSELL, J.B. Efeitos da monensina sobre a fermentação e sensibilidade de bactérias ruminais de bovinos sob dietas ricas em volumoso ou concentrado. Revista Brasileira de Zootecnia, v.30, n.1, p.254-260, 2001.

LOPES, M.A.; RESENDE, M.C.; CARVALHO, F.M.; CARMO, E.A.; CARDOSO, M.G.; SANTOS, G.; LIMA, A.L.R. Estudo da rentabilidade de sistemas de produção de leite na região de Nazareno (MG). Ciência Animal Brasileira, v.12, n.1, p.58-69. 2011.

LOPES, M.A.; DIAS, A.S.; CARVALHO, F.M.; LIMA, A.L.R.; CARDOSO, M.G.; CARMO, E.A. Resultados econômicos de sistemas de produção de leite com diferentes níveis tecnológicos na região de Lavras, MG nos anos 2004 e 2005. Ciência e Agrotecnologia, v.33, n.1, p.252-260, 2009.
LOPES, M.A.; CARDOSO, M.G.; CARVALHO, F.M.; LIMA, A.L.R.; DIAS, A.S.; CARMO, E.A. Efeito do tipo de sistema de criação nos resultados econômicos de sistemas de produção de leite na região de lavras (MG) nos anos 2004 e 2005. Ciência Animal Brasileira, v.8, n.3, p.359-371, 2007.

LOPES, M.A. CARVALHO, F.M.; LIMA, A.L.R.; DIAS, A.S.; CARMO, E.A. Efeito da escala de produção nos resultados econômicos de sistemas de produção de leite na região de Lavras (MG): um estudo multicasos. Boletim de Indústria Animal, v.63, n.3, p.177-188, 2006.

LOPES, M.A.; LIMA, A.L.R.; CARVALHO, F.M.; REIS, R.P. Efeito da escala de produção nos resultados econômicos de sistemas de produção de leite na região de Lavras (MG): um estudo multicasos. Boletim de Indústria Animal, v.63, n.3, p.177-188, 2005.

LOPES, M.A.; LIMA, A.L.R.; CARVALHO, F.M.; REIS, R.P.; SANTOS, I.C.; SARAIVA, F.H. Controle gerencial e estudo da rentabilidade de sistemas de produção de leite na região de Lavras (MG). Ciência e Agrotecnologia, v.28, n.4, p.883-892, 2004.

LOPEZ, H.; SATTER, L.D.;

WILTBANK, M.C. Relationship between level of milk production and estrus behavior of lactating dairy cows. Animal Reproduction Science, v.81, n.7, p.209223, 2004.

LUCCI, C.S.; RODRIGUES, P.H.M.; SANTOS, E.J.; CASTRO, A.L. Emprego da somatopropina bovina (BST) em vacas de alta produção. Brazilian Journal of Veterinary Research and Animal Science, v.35, n.1, p.46-50, 1998. 
Rev. Bras. Saúde Prod. Anim., Salvador, v.13, n.3, p.591-603 jul./set., 2012 http://www.rbspa.ufba.br ISSN 15199940

MARQUES, V.M.; REIS, R.P.;

SÁFADI, T.; REIS, A.J. Custos e escala na pecuária leiteira: estudo de casos em Minas Gerais. Ciência e

Agrotecnologia, v.26, n.5, p.10271034, 2002.

MATSUNAGA, M.; BEMELMANS, P.F.; TOLEDO, P.E.N.; DULLEY, R.D.; OKAWA, H.; PEDROSO, I.A. Metodologia de custo de produção utilizado pelo IEA. Agricultura em

São Paulo, v.23, n.1, p.123-139, 1976

OAIGEN, R.P.; BARCELLOS, J.O.J.; CHRISTOFARI, L.F.; NETO, J.B.

Melhoria organizacional na produção de bezerros de corte a partir dos centros de custos. Revista Brasileira de

Zootecnia, v.37, n.3, p.580-587, 2008.

SERVIÇO BRASILEIRO DE APOIO

ÀS MICROS E PEQUENAS

EMPRESAS - SEBRAE. Curso de

capacitação rural. Goiânia, 1998. 34p.

SILVA, H.A.; MORAES, H.S.K.A.; GUIMARÃES, V.A.; HACKI, E.;

CARVALHO, P.C.F. Análise da viabilidade econômica da produção de leite a pasto e com suplementos na região dos Campos Gerais - Paraná.

Ciência Rural, v.38, n.2, p.445-450, 2008.

STOCK, L.A.; CARNEIRO, A.V.; CARVALHO, G.R.; ZOCCAL, R.; MARTINS, P.C.; YAMAGUCHI, L.C.T Sistemas de produção e sua representatividade na produção de leite no Brasil. In: In: REUNIÓN DE LA ASOCIACIÓN LATINOAMERICANA DE PRODUCCIÓN ANIMAL, 20, 2007, Cuzco, Peru. Anais ... Cuzco, Peru, 2007.
TOZER, P.R.; BARGO, F.; MULLER, L.D. Economic analyses of feeding systems combining pasture and total mixed ration. Journal of Dairy

Science, v.86, n.6, p.808-818, 2003.

TUPY, O.; YAMAGUCHI, L.C.T. Identificando benchmarks na produção de leite. Revista de Economia e Sociologia Rural, v.40, n.1, p.81-96, 2002.

VASCONCELOS, J.L.M.; SILCOX, R.W.; ROSA, G.L.M. Synchronization rate, size of the ovulatory follicle, and pregnancy rate after synchronization of ovulation beginning on different days of the estrus cycle in lactating dairy cows. Theriogenology, v.52, n.2 p.10671078, 1999.

WHITE, S.L.; BENSON, G.A.; WASHBURN, S.P.; GREEN, J.T. Milk production and economic measures in confinement or pasture systems using seasonally calved holstein and jersey cows. Journal of Dairy Science, v.85, n.1, p.95-104, 2002.

YIN, R.K. Case study research: design and methods. Beverly Hills, CA: Sage Publishing. 1984.

Data de recebimento: 10/01/2012 Data de aprovação: 01/08/2012 